\title{
Vulvanın Paget Hastalığı: Olgu Sunumu
}

\section{Paget's Disease of the Vulva: A Case Report}

\author{
Ayhan ATIGAN ${ }^{1}$, Soner GÖK ${ }^{1}$, Yeliz ARMAN KARAKAYA ${ }^{2}$ \\ ${ }^{1}$ Pamukkale Üniversitesi Tıp Fakültesi Kadın Hastalıkları ve Doğum AD, Denizl \\ ${ }^{2}$ Pamukkale Üniversitesi Tıp Fakültesi Patoloji AD, Denizli
}

\begin{abstract}
$\overline{\mathbf{O} z}$
Meme dışı Paget hastalığı, kaşıntı, ağrı ve egzema gibi iyi huylu hastalıklarla ortak belirtilere sahip olan nadir bir malign neoplazidir. Vulvar hastalık, genellikle postmenopozal kadınlarda etkilenen bölge üzerinde kabuklanma veya ülserasyonlu yavaş büyüyen iyi tanımlanmış kaşıntılı bir plak olarak görülür. $\mathrm{Bu}$, tanıda gecikmeye ve sonuç olarak daha kötü prognoza yol açar.Kesin tanı, Paget hücrelerini gösteren vulva biyopsisi ile elde edilir.Tercih edilen tedavi, marjinin geniş eksizyonudur. Bizim hastamız 9 ay süren benzer yakınma öyküsü olan 73 yaşında postmenopozal bir kadındır. Tanı koymak için yapılan geniş bir biyopsinin tedavi edici rolü de vardir.
\end{abstract}

Anahtar Kelimeler: Meme Dışı Paget Hastalı̆̆ı, Vulvar Biyopsi, Vulvar Hastalik

\section{Giriş}

James Paget ilk olarak meme Paget hastalığını 1874 yılında tanımlamış olsa da, 15 yıl sonrasında Crocker meme dışı Paget hastalığını bildirmiştir (1). Meme dişı paget hastalığ 1 , vulvar malignitelerin \%12 'sini oluşturan nadir bir hastalıktır. Klinik olarak vulvar bölgede kırmızı egzamatoid lezyon görülür. Vulvar Paget hastalığı, meme ucunun derisini etkileyen bir adenokarsinom olan, meme bezindeki Paget hastalığı ile histolojik olarak yakından ilişkilidir. Meme Paget hastalığında, altta yatan glandüler doku hemen hemen tüm vakalarda kötü diferansiye intraduktal veya invaziv meme karsinomuna neden olur. Buna karşılık, vulvar Paget hastalığ1 vakalarının sadece \%4'ü bir vulvar adenokarsinom ile ilişkilidir (1). En s1k postmenopozal dönemde, ortalama 7. dekatta görülür. Cerrahi rezeksiyon, bu hasta grubunda tedavinin temelini oluşturur. Ancak, gizli intradermal retiküler yayılımlı farklı büyüme paterni nedeniyle tümörün yeterli ve tam eksizyonu zordur (2). Vulvar Paget'in histopatolojik tanisı, bol soluk sitoplazmalı Paget hücrelerinin ve belirgin nükleol ve veziküler kromatinli büyük atipik çekirdeklerin tanımlanmasıyla konur (3). Primer intraepitelyal paget hastalığının klinik olarak tanısını koymak

\begin{tabular}{|c|c|}
\hline & ORCID No \\
\hline Ayhan ATIGAN & 0000-0002-7257-0593 \\
\hline Soner GÖK & 0000-0001-8940-1879 \\
\hline Yeliz ARMAN KARAKAYA & 0000-0002-6669-9972 \\
\hline Başvuru Tarihi / Received: & 28.04 .2020 \\
\hline Kabul Tarihi / Accepted : & 29.05 .2020 \\
\hline Adres / Correspondence : & Ayhan ATIGAN \\
\hline \multicolumn{2}{|c|}{$\begin{array}{l}\text { Pamukkale Üniversitesi Tıp Fakültesi Kadın Hastalıkları ve Doğum } \\
\text { AD, Denizli }\end{array}$} \\
\hline e-posta / e-mail & dratigan@hotmail.com \\
\hline
\end{tabular}

\begin{abstract}
Extra mammary Paget disease is a rare malign neoplasm that may affect the vulva and has manifestations common to benign diseases such as itching, pain and eczema. Vulvar disease usually presents as a slow growing well-defined itchy plaque with crustations or ulcerations over the affected area in postmenopausal women. This leads to delay in diagnosis and consequent worse prognosis. The definitive diagnosis is obtained by biopsy of the vulva, which shows Paget cells. The treatment of choice is wide excision with margins. Our patient is a 73-year-old postmenopausal woman with a history of similar complaints of 9 months' duration. A large biopsy to diagnose also has a therapeutic role.

Keywords: Extra Mammary Paget Disease, Vulvar Biopsy, Vulvar Disease
\end{abstract}

zordur ve vulvanın diğer lezyonları ile karışabileceği gibi uzun yıllar gözden kaçabilir. Olgu sunumumuz ile bu nadir görülen vulvar neoplazinin klinik özelliklerini, tanı ve tedavisini literatür eşliğinde tartışmayı amaçladık.

\section{Olgu}

Hasta onamı 22.01.2020 tarihinde alınmıştır. Gravida: 3, Parite: 3 (vajinal doğum), 73 yaşındaki hasta yaklaşı dokuz aydır devam eden vulvar kaşıntı, sızı ve yanma şikayetleriyle jinekoloji polikliniğimize başvurdu. 8 yıl önce desensusuteri nedeniyle histerektomi operasyonu olduğu öğrenildi. Hastamızın hipertansiyon rahatsızlığı olup antihipertansif ve asetilsalisik asit kullanımı mevcuttu. Kolonoskopi, sistoskopi, mamografi ve meme ultrasonografisi normaldi. Sağ vulva ödemli ve hiperemik görünümlü olmakla birlikte aynı taraf labiummajus üzerinde toplam boyutu yaklaşık $3 \times 1$ cm'lik yüzeyi erode lezyon saptandı. Hastanın yoğun lökoresi mevcuttu.

Vulvar Paget tanısı almış hastaların en yaygın klinik bulgu ve şikayetleri arasında vulvar kaşıntı, ağrı ve ekzamatöz cilt lezyonu bulunur. Bu belirtiler kontakt dermatit, kandidiyazis, tineacruris, sedef hastalığ 1 , liken simpleks ve seboreik dermatit gibi çeşitli iyi huylu hastalıklarda da yaygındır (3). Bu nedenle hastalar geç tanı alabilmektedir.

Lezyondan alınan biyopsi sonucunda ekstra mamarian paget hastalığı ve vulvar intraepitelyal neoplazi (VIN II- Warty tip) teşhisi konuldu. Hastanın papsmear ve hpvpcr sonucu negatifti. Alınan spesimenin mikroskobik incelenmesinde; hematoksilen-eozin (H-E) boyamada epidermis içine pagetoid dağılım gösteren iri hiper kromatik nükleuslu, geniş eozinofilik sitoplazmalı atipik hücrelerden oluşmuş tümöral proliferasyon 
izlenmiştir (Resim 1-3). Yapılan immünohistokimyasal (İHK) incelemede CK7 (+) (Figür 3), GATA-3(+), CEA fokal(+), AR(+), p53 $\% 15(+)$, CK20(-), CDX-2(-), MUC-2(-), ER(-), PR(-), CerbB-2 skor 0, Melen-A(-), S100(-), HMB45(-) tespit edilmiştir. GCDFP15(-), p16(+), HPV HR(-), Ki-67 \%20(+)'tir. PAS ile (+) boyanma izlenmiştir. Operasyon sonrası ayrıntılı patolojik inceleme sonucunda paget hastalığı ve VIN II için cerrahi sinırlar temiz olarak bulundu. Hastadan ileriki kontrollerinde tekrar biyopsi alınması kararlaştırıldı.

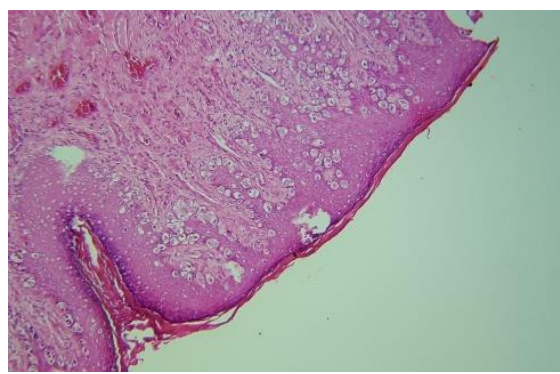

Resim 1. Epitelde pagetoid dağılım gösteren hücreler, HE, $x 100$

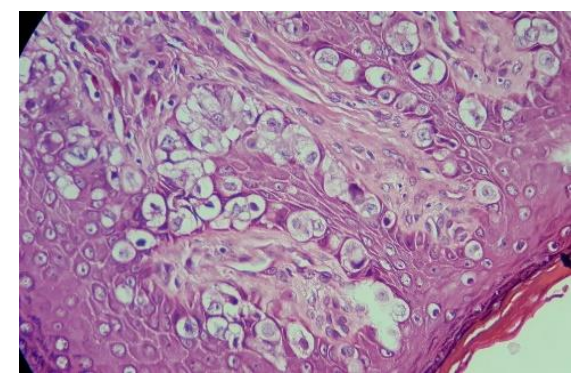

Resim 2. Paget hücreleri, H-E, x200

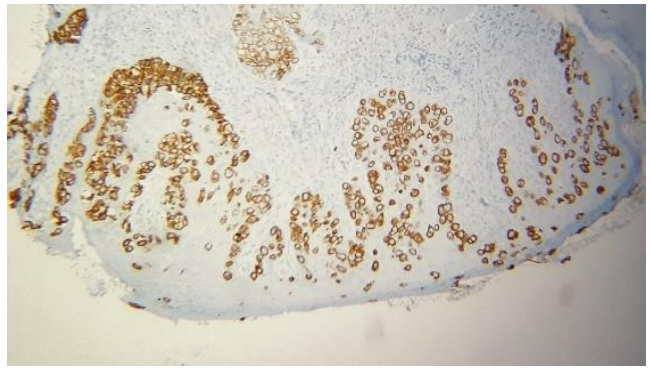

Resim 3. CK7 pozitif paget hücreleri, İHK, x100

\section{Tartışma}

Vulvanın Paget hastalığı, literatürde sadece sınırlı sayıda vaka bulunan nadir bir durumdur. Postmenopozal dönemde vulvar maligniteler belirgin bir lezyon olmadan vulvada kaşıntıya neden olabilirler. Meme dışı Paget hastalığı için kaşıntı ve hiperkeratoze pembe egzematoid lezyon en sik görülen semptomlardır. Lökoplaki izlenimine yol açan kalın vulvar deri Paget hastalığı için patognomiktir (3). Histopatolojik incelemede, PAS pozitif Paget hücrelerinin görülmesinin yanı sıra immünohistokimyasal boyamada CK7 ve CEA pozitifliği tanıda yardımcıdır. Ayrıca, S-100 ve HMB-45 boyamaları malign in situ melanomdan ayırt etmek için kullanılır (4). Bizim vakamızda da PAS, CK7 ve CEA pozitif iken S-100; HMB-45 negatifti.Paget'in vulva hastalığı son zamanlarda neoplastik hücrelerin kökeni temelinde alt sınıflara ayrılmıştır (5): Tip 1; primervulvarkutanöz kökenlidir, Tip 2; ilişkili bir komşu primer anal veya rektal adenokarsinomun bir belirtisidir, Tip 3; mesane (ürotelyal) neoplazinin bir belirtisidir.

Primer intraepitelyal vulvar Paget hastalığının en çok kabul gören tedavisi geniş ve derin lokaleksizyondur. Her vaka da olmasa da küçük boyutlu tümörlerde cerrahiye alternatif olarak topikal \%5 imikuimod, \%3.5 bleomisin, 5flurourasil, $\mathrm{CO}_{2}$ lazer veya radyoterapi denenebilir (3). Cerrahi sırasında temiz sınırlar elde etmek için; frozen kesitler veya flöresin enjeksiyonu ve UV 1 şık kullanılarak vasküler lezyonun görüntülenmesinden faydalanılabilinir. Negatif cerrahi sınır ile gerçekleştirilen eksizyon sonrasında bile \%30'ları bulan yüksek nüks oranı, büyük olasılıkla hastalığın multifokal yapılanmasının bir sonucudur (6). Bu durum göz önünde tutulduğunda, hastalar uzun süre takip edilmelidir. Altta yatan ilişkili bir malignite vakaların \%12-33'ünde ortaya çıkabilir, bu nedenle tüm hastalar gizli metastazlar için kapsamlı bir şekilde araştırılmalıdır (7). Hastamızın yapılan ileri tetkiklerinden sonra Tip 1, vulvar kutanöz kökenli Paget hastalığı olduğu tespit edilmiştir. Ancak hasta takiplerini aksatmaması konusunda uyarıldı.

Meme dışı Paget hastalığı; kontakt veya irritan dermatit, intertrigio, seboreik dermatit, tineacruris, kandidiyaz, psoriasis ve Bowen hastalığını taklit edebildiğinden yıllarca teşhis edilmeyebilir. $\mathrm{Bu}$ nedenle, jinekoloji polikliniğine kaşıntılı egzematoid lezyonla başvurularda akılda tutulması gereklidir. Bu vaka, ilk adım tedavi sonrası gerilemeyen bütün lezyonlardan biyopsi alma ihtiyacını güçlendirir. Ayrıca vakamızın literatürdeki vulvar Paget vakalarından farklılığı aldığımız biyopsi ile insidental olarak VIN II tanısı konulmasıdır.

18. Ulusal jinekoloji ve obstetrik kongresine (TJOD 2020) poster bildiri olarak kabul edilmiştir.

Hasta Onamı: Hasta onamı 22.01.2020 tarihinde alınmıştır.

\section{Kaynaklar}

1. Parker LP, Parker JR, Bodurka-Bevers D, et al. Paget's disease of the vulva: pathology, pattern of involvement, and prognosis. Gynecol Oncol. 2000;77(1):183-9.

2. Dogan A, Hilal Z, Krentel H, et al. Paget's disease of the vulva treated with imiquimod: case report and systematic review of the literature. Gynecol Obstetric Invest. 2017;82(1):1-7.

3. Gavriilidis P, Chrysanthopoulos K, Gerasimidou D. ExtramammaryPaget'sdisease of the vulva. BMJ Case Rep. 2013;11:21-3.

4. Hillmann BR, Pereira AA, Sommacal LF. ExtramammaryPagetDisease of the Vulva - Case Report. Rev Brasil Ginecol Obstet. 2016;38(10):524-8. 
5. Wilkinson EJ, Brown HM. Vulvar Paget disease of urothelial origin: a report of three cases and a proposed classification of vulvar Paget disease. Hum Pathol. 2002;33:549-54.

6. Black D, Tornos C, Soslow RA, Awtrey CS, Barakat RR, Chi DS. The outcomes of patients with positive margins after excision for intraepithelial Paget's disease of the vulva. Gynecol Oncol. 2007;104(3): 547-50.

7. Chandra JJ. Extra mammary Paget's disease: prognosis and relationship to internal malignancy. J Am Acad Dermatol. $1985 ; 1009-14$ 